КАРПОВА Дарья Николаевна - кандидат социологических наук, старший преподаватель кафедры социологии Московского государственного института международных отношений (университет) МИД РФ (119454, Россия, г. Москва, nр-кт Вернадского, 76; d.karpova@inno.mgimo.ru)

ПРОСКУРИНА Александра Сергеевна - аспирант кафедры социологии Московского государственного института международных отношений (университет) МИД РФ (119454, Россия,

2. Москва, пр-кт Вернадского, 76; a.proskurina@inno.mgimo.ru)

\title{
СОЦИОТЕХНИЧЕСКИЙ ПОВОРОТ В ИССЛЕДОВАНИИ ЦИФРОВИЗАЦИИ ОБЩЕСТВА
}

\begin{abstract}
Аннотация. Для понимания сущности реалий цифровизации общества и построения аналитико-прогностических картин с точки зрения фундаментальной теории необходимо обращаться не только к социологическому взгляду, но и к дискурсу техническому, к специалистам в области информатики, компьютеризации, программирования и других цифровых технологий. В рамках настоящей работы авторы концептуализируют понятие цифровизации на основе сравнительного анализа социологического и технологического взглядов. Также авторы аналитически разделяют термины цифровизации социума и социальной цифровизации.
\end{abstract}

Ключевые слова: цифровизация, социальная цифровизация, трансформация профессии социолога, методология социологии

$\mathrm{B}^{\mathrm{P}}$ России сложился устойчивый тренд создания необходимых условий для развития цифрового общества. Утвержденная распоряжением Правительства РФ № 1632-р от 28 июля 2017 г. программа «Цифровая экономика Российской Федерации» предполагает качественное переориентирование ключевых секторов экономики на новый формат функционирования 1 . Реализация настоящей Программы требует тесного взаимодействия науки и государства, однако в социологии на данный момент не установлено общепринятое определение и не концептуализировано понятие цифровизации общества, а также не классифицированы функциональные и дисфункциональные особенности этого процесса. Именно поэтому актуальность и научная значимость данного исследования обусловлена необходимостью теоретико-методологического осмысления проблемы цифровизации через призму технических и социальных наук.

\section{К обоснованию идеи социотехнического поворота}

Очевидно, что в изучении цифровизации и компьютеризации общества преуспели именно технические науки. «Цифра», «цифровой», «оцифровывание» - активные категории понятийного аппарата инженеров. В этой связи обосновывается актуальность выбора социотехнического поворота в качестве основной методологической базы работы и нового междисциплинарного подхода. Стоит добавить, что дееспособность подобных поворотов в социологии предложил известный английский социолог Дж. Урри, однако в рамках исследования «поворота сложности» он ратовал за возможность научной интеграции социальных и естественных наук, исходя из того, что у них может быть общее предметное поле, как раз касающееся многогранных проблем сложности [Urry 2003]. Это отнюдь не свидетельствует о теоретико-методологических изъянах

\footnotetext{
1 Программа «Цифровая экономика». Доступ: http://static.government.ru/media/files/9gFM4F Hj4PsB79I5v7yLVuPgu4bvR7M0.pdf (проверено 23.12.2019).
} 
современных социологических парадигм. Проблема в ином: «организованный, рациональный» социум буквально на наших глазах стал быстро «устаревать», обретая качественно другие характеристики - быстро увеличивающуюся сложность с новой генерацией рисков. Чтобы адекватно анализировать сложный мир, пришлось не улучшать и подправлять существующий инструментарий, а создавать качественно иные парадигмы, основанные не только на интеграции собственно социологических теорий, но и на синтезе социологических подходов с другими науками.

\section{Технический и социологический дискурсы цифровизации}

Технологическое осмысление процесса цифровизации находит свое отражение в нескольких векторах исследований. Одним из самых популярных направлений можно считать Интернет вещей и связанные с ним вопросы: связь вещей друг с другом и с глобальной сетью; связь Интернета вещей с несетевыми вещами и пространствами; степень автономности Интернета вещей и необходимость такой автономности. Другое направление - компьютерные расширения человека и сближение человека и компьютера по их свойствам. Здесь исследования направлены на компьютеризацию органов чувств (компьютерное зрение, компьютерное осязание, ориентация в пространстве и на местности), компьютерное мышление (нейросети, принятие решений, алгоритмизация) и, с другой стороны, возможность применения этих расширений совместно с человеческим организмом (системы-ассистенты для принятия решений и анализа, протезы, усиление зрения и слуха, дополненная реальность). Цифровизация рассматривается и как проникновение компьютерных технологий в профессии (с точки зрения конкретных решений для них), а также она связана с изменением человеческого поведения через взаимодействие с абстрактными системами, «черными ящиками» - это технологии продаж, технологии выдачи в социальных сетях и поисковых системах, поиск работы и наем, игроизация как технологическое решение, ПО для исследований, учета, аналитики, системы уровня государств и мировых регионов. Области науки, исследующие цифровизацию с точки зрения технологий, - это программирование, физика, биохимия, медицина, математика и др., т.е. весь комплекс технических и естественнонаучных областей. Следует обратить внимание на то, что технологический дискурс цифровизации связан не с последствиями для общественных систем, а с представлением решений для запросов, их реализации с точки зрения физической инфраструктуры и принципов работы с данными. Поле технологических исследований в этой области - технологическая среда, а из более «общественных» сфер можно отметить области сертификации (доступ к технологиям) и юридические вопросы. Вопросы этики работы по цифровизации рассматриваются, но отдаются на суд специализированных органов и не представляют собой центральный предмет исследования.

Цифровизация как социальное явление получила распространение в 60-70-х гг. ХХ в., и характеризуют ее три ведущие характеристики:

1) все виды контента переходят из аналоговых, физических и статичных в цифровые, одновременно становятся мобильными и персональными. При этом индивид получает возможность контролировать свой личный контент, направлять информационные запросы, формировать индивидуальную траекторию информационной деятельности;

2) осуществляется переход к простым технологиям коммуникации (технология становится лишь средством, инструментом общения), ведущая характеристика устройства и технологии - управляемость;

3) коммуникации становятся гетерогенными: вертикальная, иерархичная 
коммуникация теряет актуальность, происходит переход к сетевой структуре коммуникации.

Социологический дискурс изучаемой проблематики актуализируется заслугами прежде всего западных социальных исследователей. Одним из первых социологов, который уже в конце 1980-х гг. сумел оценить важность происходящих в обществе информационно-технологических изменений, стал испаноамериканский ученый М. Кастельс. В теории сетевого информационального общества он развивает дискуссию об изменении качественных характеристик социума, в котором логика социальных структур индустриального модерна заменилась логикой структур сетевых информационных потоков. М. Кастельс привлекает общественное внимание к проблеме социального сдвига от традиционных средств массовой информации (телевидение, печатная пресса, радио) к системе сетевых горизонтальных коммуникационных потоков Интернета, которые способны упорядочивать сами пользователи сети Интернет [Castells 2010: 27]. Он предложил внедрить понятие «массовая самокоммуникация» (mass self-communication) для характеристики новых форм взаимодействия индивидов. Массовой она является вследствие способности охватить неограниченное число интернет-коммуникантов во всем мире. Префикс само- характеризует данный тип коммуникации как самостоятельно формируемый и освобожденный от возможных посредников, произвольно или намеренно искажающих интеракцию. Иными словами, любой индивид, имеющий доступ к Интернету, способен 1) создать свое личное виртуальное пространство (персональные страницы в социальных сетях, живые журналы, видеохостинги), 2) редактировать его, пополняя любыми (даже искаженными) данными, а при желании 3) сделать его открытым для широкой общественности, при этом никакая «третья сторона» на него повлиять не может. Именно этой доступной открытостью объясняется популярность «народной» энциклопедии Википедии, международных социальных сетей Facebook, MySpace, видеохостинга YouTube и др.

Несколько позже мировые социологи приходят к мысли об уже свершившейся мобильной революции. Реакцией на массовое распространение мобильного Интернета становится зарождающийся в социологии дискурс, связанный с миниатюризированной цифровой мобильностью (miniaturized mobility), который в начале нулевых годов становится научным поводом для формулирования инновационного методологического подхода британских социологов Дж. Урри и Э. Эллиотта. В частности, Э. Эллиот приходит к выводу, что мобильные технологии, которые условно «помещаются в кармане», способствуют мгновенной коммуникации, но одновременно приводят к изменениям в социальных отношениях [Elliott 2013: 72]. С одной стороны, облегчаются многие сферы быта, связанные с управлением распорядком дня или запоминанием определенных дат и событий, с другой - технологии заменяют естественные, данные природой «инструменты»: память, логику, воображение, грамотность. Например, легче решить конфликт лицом к лицу, чем в Интернете, в т.ч. и потому, что трудно определить источник конфликта, когда тон голоса, язык тела и выражение лица отсутствуют. Это часто имеет место в текстовой коммуникации: комментарий, который должен быть шуткой, может быть неверно истолкован как оскорбительное замечание. Анонимность и отсутствие мимических подсказок и языка тела делают кибериздевательства проще, чем в автономном режиме [Гришаева, Куликова 2018: 33]. А широкое распространение киберагрессии среди подростков коррелирует с одиночеством и социальной эксклюзией в обычной жизни.

Под воздействием новых цифровых технологий происходят изменения не только в способах коммуникации и социальных отношениях, но и в лично- 
сти человека. Особого внимания в этом контексте заслуживают исследования австралийского социолога Д. Лаптон в области изучения цифровой самости и цифрового «Я». В своей последней работе «Data selves» автор рассуждает и о персональных данных, которые перестают принадлежать человеку, и о последствиях плотной интеграции человека и техники [Lupton 2019: 44]. Последняя проблема беспокоит представителей социальной науки. И хотя в общественном сознании формируются весьма положительные представления о достижениях и последствиях процесса цифровизации, социологи призваны выявлять его побочные эффекты, которые негативно сказываются на функционировании общества и поведении людей. В частности, образование новых реалий власти и властных отношений, надзора, а также размывание границ частной жизни (чипирование техники и людей, следовательно, сбор персональных данных, в т.ч. биометрических) приводит к созданию центров больших данных, т.е. гигантских монополий, осуществляющих сбор объемной информации практически со всех компьютеров, существующих в мире. Власть мировых цифровых гигантов, таких как Google, Apple, Microsoft, Facebook, Amazon, которым мы доверяем свою личную информацию и которые осуществляют тотальный контроль над процессами цифровизации в мире, «представляет фундаментальную угрозу демократии» [Кравченко 2019: 28]. В уже упомянутой выше работе Д. Лаптон автор замечает, что постоянное использование людьми самоотслеживающихся устройств и иных цифровых технологий аккумулирует персональные данные миллионов людей, которые могут быть использованы в корыстных целях третьими лицами. Как правило, большинство пользователей мобильными «умными» гаджетами не осознают, куда попадают их данные, или попросту этим не интересуются.

Разделение терминов «цифровизация социума» и «социальная цифровизация» проводится западными социологами через словообразование. Цифровизацию социума, под которой понимается переход от аналоговых средств к цифровым, обозначают как digitization (буквально - цифризация). Социальные же аспекты этого перехода обозначают термином digitalization - «цифровизация». Оба процесса оказывают воздействие на современное общество, однако существуют значимые различия в их социологическом осмыслении.

Для того чтобы разделить бифункциональное (техническое и социальное) назначение слова, некоторые западные ученые настаивают на разделении понятий «цифризация» (digitization) и «цифровизация» (digitalization) как принципиально разных и невзаимозаменяемых определений процесса оцифровывания социальной среды. В частности, американские исследователи С. Бреннен и Д. Крайс предложили понимать под цифризацией материальный процесс конвертирования потоков информации в цифровые биты, тот самый процесс оцифровывания, о котором шла речь, а цифровизацию - способом, при котором многие сферы социальной жизни индивидов реструктурируются под воздействием цифровой коммуникации и медиаинфраструктуры [Brennen, Kreiss 2014]. Термин digitization связан с восприятием технологий как внешнего инструмента, изменяющего привычные реалии. Такой подход характерен для экспертов, принимающих материальные, экономические, юридические решения, где технология - это материальный участник общественной жизни. Специалисты технической области предположительно воспринимают термин «цифровизация» именно с этих позиций, т.к. они имеют дело с механизмами, устройствами, кодами - тем, что можно «потрогать руками», что они создали сами. Такие устройства и коды не несут дополнительной смысловой нагрузки, т.к. они являются инструментом, выполняющим функцию. Последствия создания этих инструментов могут выражаться разве что абстрактно - в виде воз- 
можных моральных дилемм планетарного масштаба, как это случилось с изобретением тротила и атомного оружия. Такое восприятие рационально с точки зрения представителей технических областей, т.к. они не стремятся изменить обшество, а действуют из необходимости выполнить поставленную задачу. Аналогичную рациональность можно предположить для юридической, экономической и политической сфер. С точки зрения юриста переход на «цифру»это общественное изменение, добавляющее ряд аспектов к уже существующим отношениям. Так, необходимо переопределять понятие субъектности, а также уточнять политику ответственности в области персональных данных [Талапина 2018: 7-8]. В экономике производство обретает новые характеристики, в первую очередь повышение мощностей и изменение потоков информации, что требует осмысления только новых решений и порядка действий [Басаев 2018: 37]. В политике цифровизация - объект принятия решений; в России она связана прежде всего с указами президента и федеральными законами, утверждающими ее в качестве политической линии. Таким образом, цифровизация социума означает восприятие цифровых технологий как ресурса, который необходимо регламентировать, распределять, производить и использовать.

Другой термин, digitalization, вероятно, впервые был введен в Оксфордский словарь английского языка в середине 1950-х гг. и был заимствован из информационно-технологической терминологии. Изначально под дигитализацией понимался процесс конвертирования данных в цифровой формат. Постепенно оно стало экстраполироваться на общественные науки со значением социальной проблемы. В этом значении цифровизация впервые появляется в научном дискурсе в статье «Человечество и компьютеры» ученого Р. Уошала, опубликованной в американском журнале North American Review в 1971 г. Под ней автор понимал процесс внедрения компьютеризированных принципов развития общества [Wachal 1971: 32]. В те годы Р. Уошал использовал это понятие только для обозначения тенденций массового внедрения цифровых технологий в повседневную жизнь. Повсеместная цифровизация привела к появлению нового дискурса в социальных науках, связанного с проблемами влияния новых виртуальных технологий на социальную жизнь общества. Конечно, в большей степени процесс цифровизации изучен в рамках технических и естественных наук. И для цифровизации технической они имеют неоспоримое значение, однако теории цифрового звука, цифрового телевидения, цифрового Интернета непригодны для изучения социальных последствий цифровизации. Пожалуй, из всех социальных наук успешнее всего в области изучения цифровизации продвинулись экономисты, которые уже достаточно устойчиво применяют термин «Цифровая экономика». Ведутся научные экономические исследования, разрабатываются концепции цифровой экономики, закладываются теоретические основы под такие составляющие, как теория цифровой экономики, промышленности, производства; появились исследования и теоретические обоснования цифровой власти, цифрового образования [Ницевич 2018: 20].

Исходя из рассмотренных особенностей процесса цифровизации и поставленных ранее исследовательских задач, сформулируем социологическое определение цифровизации социума и социальной цифровизации.

Цифровизация - это процесс преобразования любой информации в цифровую форму, распространяющийся как на макро-, так и микроуровни общества (государство, организация, человек), физические структуры и предметы. Цифровизация расширяет технические и биосоциальные возможности человека, одновременно устанавливая над ним новый вид всепроникающего контроля. Цифровизация регламентируется юридически, экономически, технически, политически и социально. Цифровизация может иметь визуальное 
выражение через интерфейсы взаимодействия (Интернет, дисплеи) или осуществляться на уровне организации жизни, становясь доступной только для специалистов.

Цифровизация социума, следовательно, - это цифровизация, осуществляемая в контекстах исторически обусловленных социальных форм совместной жизни и деятельности.

Социальная цифровизация с точки зрения русского языка - термин, указывающий на два возможных аспекта цифровизации. Согласно словарному определению, «социальный (от лат. socialis - общий, общественный) - это название всего межчеловеческого, т.е. всего того, что связано с совместной жизнью людей, с различными формами их общения, в первую очередь того, что относится к обществу и общности, что имеет общественный и общностный характер». То есть, с одной стороны, «социальный» - это направленный на благо общества (в отличие от «асоциального», «антисоциального»); с другой «социальный» - это имеющий связь с обществом, где общество может быть как источником, так и «получателем». Этот термин исключает чисто техническое, материальное восприятие процесса цифровизации и средств ее осуществления. Социальная цифровизация касается общественных отношений, возникающих на почве появления в повседневности цифровых форм и технологий. Речь идет о новых целях, новых средствах их достижения. Увеличение скоростей приводит к тому, что Дж. Урри обозначает как повороты в общественном развитии: изменяется восприятие времени, пространства, места, общественного и личного. Возникают «текучие» реалии (3. Бауман) - всепроникающие, с долгосрочными последствиями, нестабильные, незавершенные. Рутина становится способом преодоления неопределенности, однако преодолением симптоматическим, а не радикальным, потому что полное ее преодоление уже невозможно. Все эти последствия становится сложно концептуализировать, объяснить, понять и оценить, если воспринимать цифровые технологии как очередной инструмент решения задач. Однако последствия этих изменений в общественном развитии значительны как для самого человека, так и для планеты в целом: современный катастрофизм, в отличие от схожих ситуаций в прошлом, может принести неизбежные масштабные последствия, что будет являться следствием не самого технологического прогресса, а именно общественных отношений на его почве [Бек 2000: 42-43]. Исследуемому феномену можно дать следующее определение.

Социальная цифровизация - это глобальный процесс преобразования информации в цифровую форму, который радикально изменяет характер межгрупповых и межличностных взаимоотношений людей; условия существования социума становятся зависимыми от цифровых технологий, что приводит к возникновению ненамеренных и малоконтролируемых последствий.

Признаки социальной цифровизации:

1) внедрение цифровых технологий в сферы, затрагивающие общественные отношения;

2) активная роль общества в вопросах внедрения;

3) возникновение ненамеренных последствий в силу сложности, недоступности технологий неспециалистам;

4) отношения власти и контроля включают в себя цифровые технологии.

Проведенное терминологическое разделение указывает на необходимость построения «мостов» между двумя подходами к цифровизации. Работа исключительно с цифризацией лишает исследователей и экспертов возможности глубинного анализа влияния технологических реалий на общественные, что, в свою очередь, не позволяет принимать эффективные управленческие реше- 
ния. С другой стороны, исключительно социологический анализ последствий проникновения цифрового в аналоговый социум не будет полноценным, если социолог плохо представляет себе технологический аспект этого проникновения.

Полученные определения высвечивают ряд областей, которые в дальнейшем требуют экспертного комментария методом глубинных интервью для решения следующих исследовательских задач.

1. Определить список регуляторов цифризации. Это позволит выявить, каким образом общественная структура контроля влияет на фактическую работу специалиста в области технического обеспечения.

2. Через анализ повестки дня - ключевых, значимых, перспективных в восприятии технологических экспертов направлений работы - обнаружить значимые связи цифризации и цифровизации, а также источники определения важности соотношения направлений с другими общественными институтами - все, что сделает вклад в понимание фактической, а не юридической связи между исследуемыми реалиями.

3. Выявить соблюдение этических норм в работе технологической стороны цифровизации. Так как эксперт - член общества, он является носителем конкретных групповых и общественных морально-этических систем. Также необходимо определить, каковы фактические границы содействия интересам и требованиям правительств и других властных и контролирующих институтов.

4. Общественные отношения обеспечиваются различными видами ресурсов - как материальными, так и нематериальными. Следует показать правила и нормы распределения материальных ресурсов (вопросы монетизирования цифризации). Нематериальные ресурсы - статус, признание, культура труда и профессии - могут формироваться в т.ч. за счет причастности эксперта к научной работе или иным формам экспертного признания. Соотношение ресурсов различных типов и принципы их формирования, распределения внутри процесса позволят соотнести конкретные, понятные несоциологу реалии и научное их восприятие.

5. Дополнить эмпирическое понимание масштаба и характера последствий цифризации и цифровизации. Эксперт, будучи членом общества, не может не учитывать возможные последствия своей работы, особенно осознавая ее реальные характеристики. Учитываются ли социальные последствия при технологической разработке, или же этот вопрос в процессе разработки технологий не возникает?

Согласно основным направлениям исследований в технологической области прирост знания будет достигнут через глубинное интервью со специалистами в разработке Интернета вещей, компьютерных «органов чувств», с разработчиками программных решений для организаций, а также представителями научной общественности, кандидатами и докторами технических наук, научными сотрудниками исследовательских институтов, а также с экспертами в области юридического сопровождения технических разработок и сертификации.

Очевидно, что в ближайшие годы важнейшие сектора экономики и общество в целом будут существовать в рамках парадигмы цифровой действительности. Процессы интеграции технологий в социум остановить невозможно, и вряд ли это стоит делать. Однако наряду с функциональными, очевидно «полезными» свойствами цифровых изменений, налицо трансформации дисфункционального толка как на структурном, так и на поведенческом уровнях. Наша основная задача заключается в том, чтобы продолжить изучение явных и латентных проявлений цифровизации по всех видах человеческой деятельности, а также придать изучаемым явлениям гуманистический стержень во избежание необ- 
ратимых последствий рискогенного технократического будущего [Кравченко 2013].

Статья подготовлена в рамках гранта МГИМО МИД России на выполнение научных работ молодыми исследователями.

\section{Список литературы}

Басаев 3.В. 2018. Цифровизация экономики: Россия в контексте глобальной трансформации. - Мир новой экономики. № 4. С. 32-38.

Бек У. 2000. Общество риска. На пути к другому модерну. М.: ПрогрессТрадиция. 384 с.

Гришаева С.А., Куликова О.А. 2018. Социально-психологические особенности процесса трансформации социальной структуры общества и процесса коммуникации в цифровом пространстве. - Цифровая социология. Т. 1. № 1. C. 29-34.

Кравченко С.А. 2013. К обоснованию гуманистической теории сложности общества. - Вестник МГИМО Университета. № 1(28). С. 180-184.

Кравченко С.А. 2019. Многоликость метаморфоз: о новациях двух канадских социологов. - Социс. Социологические исследования. № 2. С. 26-35.

Ницевич В.Ф. 2018. Цифровая социология: теоретико-методологические истоки и основания. - Цифровая социология. Т. 1. № 1. С. 18-28.

Талапина Э.В. 2018. Право и цифровизация: новые вызовы и перспективы. Журнал российского права. № 2(254). С. 5-17.

Brennen S., Kreiss D. 2014. Digitalization and Digitization. - Culture Digitally. 08.09. URL: http://culturedigitally.org/2014/09/digitalization-and-digitization/ (accessed 23.12.2019).

Castells M. 2010. The Information Age: Economy, Society and Culture. Vol. I. The Rise of the Network Society. Oxford: Wiley-Blackwell. 624 p.

ElliottA. 2013. Miniaturized Mobilities: Transformations in the Storage, Containment and Retrieval of Affect. Psychoanalysis. - Culture \& Society. Vol. 18. Is. 1. P. 71-80.

Lupton D. 2019. Data Selves. Polity Press. 208 p.

Urry J. 2003. Global Complexity. Cambridge: Polity Press. 184 p.

Wachal R. 1971. Humanities and Computers: a Personal View. - North American Review. No. 8. P. 30-33.

KARPOVA Dar'ya Nikolaevna, Cand.Sci. (Soc.), Senior Lecturer at the Chair of Sociology, Moscow State Institute of International Relations, University of the Ministry for Foreign Affairs of Russia (76 Vernadskogo Ave, Moscow, Russia,119454; d.karpova@inno.mgimo.ru)

PROSKURINA Aleksandra Sergeevna, postgraduate student at the Chair of Sociology, Moscow State Institute of International Relations, University of the Ministry for Foreign Affairs of Russia (76 Vernadskogo Ave, Moscow, Russia,119454; a.proskurina@inno.mgimo.ru)

\section{SOCIOTECHNICAL TURN IN THE STUDY OF DIGITALIZATION OF SOCIETY}

\footnotetext{
Abstract. The aim of the article is to conceptualize the notion of digitalization of society through an analytic comparison of existing sociological and technical approaches to digitalization. The article describes the contextual environment of the origin and development of the sociological discourse of the digitalization of society. The analysis was used to propose and conceptualize the sociological definition of digitalization of society and social digitalization. Digitalization of society is digitalization carried out in the context of historically conditioned social forms of life and activity. Social digitalization is a
} 
global process of transforming information to digital form that radically changes the nature of intergroup and interpersonal relationships of people. The conditions of social existence become dependent on digital technologies, which lead to unintended and uncontrollable consequences. The authors attempt to bridge the knowledge gap by turning to the technological discourse of digitalization in order to complement the exclusively sociological discourse. This combination of two distant areas has provided a deeper understanding of the impact of digital technology on public life beyond the interpretation of changes within actor-networking or postmodern terms.

Keywords: digitalization, social digitalization, transformation of sociological profession, methodology of sociology

НАЗАРОВ Михаил Михайлович - доктор политических наук, главный научный сотрудник Института социально-политических исследований РАН (119333, Россия, г. Москва, ул. Фотиевой, 6 , корn. 1; vy175867@yandex.ru)

\title{
ПОЛИТИЧЕСКАЯ КОММУНИКАЦИЯ В ОБЩЕСТВЕ ПОСТПРАВДЫ: ГРАЖДАНЕ И ДОВЕРИЕ К ИНФОРМАЦИОННЫМ ИСТОЧНИКАМ
}

\begin{abstract}
Аннотация. В статье обсуждается доверие к медиа как важная составляющая политической коммуникации в российском обществе. Согласно эмпирическим данным, в целом доверие к медиа является невысоким; граждане склонны не доверять ТВ, прессе, радио в большей степени, нежели Интернету. Доверие к медиа опосредуется отношением к текущей социальной ситуации и политической системе, $к$ ключевым институтам власти, к оценкам результатов деятельности медиа. Автор обосновывает, что размывание доверия к медиа обусловлено как кризисными тенденциями глобального капитализма, так и технологическими и социокультурными трендами современной среды постмодерна.

Ключевые слова: доверие к медиа, политическая коммуникация, постправда, цифровая медиасреда, телевидение, Интернет
\end{abstract}

B рамках данной публикации хотелось бы продолжить обсуждение, которое идет на страницах журнала в связи с проблематикой социально-гуманитарных следствий цифровизации [Лапшин 2019], ее влияния на политические коммуникации в обществе, в т.ч. на доверие к медиа [Дугин 2018]. Понятие доверия в широком смысле трактуется как чувство или убеждение, что какомулибо лицу, обстоятельству можно верить. Доверять - значит полагаться на коголибо, не сомневаться в его честности. В социально-гуманитарной традиции акцент делается на социальной роли доверия как свойства, обеспечивающего функционирование социального организма, снижающего информационную асимметрию в процессе социального взаимодействия.

Исследовательский контекст. Актуальность анализа доверия применительно к сферам политической коммуникации и власти обусловлено тем, что функционирование демократических процессов и широкого общественного участия предполагает наличие информированных граждан, принимающих обоснованные решения. Рассматривая доверие к медиа как некоторое отношение, можно выделить две стороны: тех, кто доверяет, и тех, кому доверяют. Соответственно, в фокусе анализа оказываются те или иные аудитории и информационные источники. В структуре доверия к источникам, как правило, выделяют три основные составляющие. Во-первых, это доверие к медиа - посредникам, каналам, с помощью которых социально-политическая, культурная и прочая информация передается аудитории. Во-вторых, это доверие к собственно источнику, «про- 